Discussion Paper No. 13-008

\title{
How Can Pure Social Discounting be Ethically Justified?
}

Wolfgang Buchholz and Michael Schymura

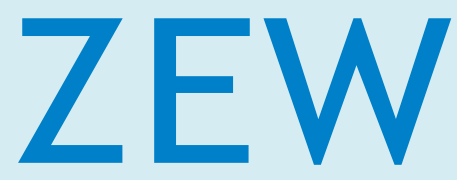

Zentrum für Europäische Wirtschaftsforschung $\mathrm{GmbH}$

Centre for European Economic Research 
Discussion Paper No. 13-008

\section{How Can Pure Social Discounting be Ethically Justified?}

Wolfgang Buchholz and Michael Schymura

Download this ZEW Discussion Paper from our ftp server:

http://ftp.zew.de/pub/zew-docs/dp/dp13008.pdf

Die Discussion Papers dienen einer möglichst schnellen Verbreitung von neueren Forschungsarbeiten des ZEW. Die Beiträge liegen in alleiniger Verantwortung der Autoren und stellen nicht notwendigerweise die Meinung des ZEW dar.

Discussion Papers are intended to make results of ZEW research promptly available to other economists in order to encourage discussion and suggestions for revisions. The authors are solely responsible for the contents which do not necessarily represent the opinion of the ZEW. 


\section{ExeCUtive Summary}

Evaluation across time is a recurrent and highly contentious topic in economics. The analysis of the profitability of public projects was introduced by Jules Dupuit, a french engineer. Dupuit's concept of cost-benefit analysis has also been used to evaluate the long-term effects of climate change. Due to the fact of today incurring costs and longterm benefits occurring in the future, the results from such long-term evaluations depend crucially from the chosen intertemporal welfare criterion. The publication of the Stern Review in 2006 has brought the ethical dimension of this issue to the fore and provoked a heated dispute. But it seems that some contributions dealing with the Stern Review, and the Review itself, mixed up normative and positive issues to defend the own position.

In two recent contributions in Environmental and Resource Economics, there was dispute about intertemporal welfare economics between Partha Dasgupta and John Roemer about the correct interpretation of the topic. The aim of this work is to bring together economic and philosophical reasoning about justice and intergenerational equity in the context of climate change. So we adopt the normative view in order to present the most important ethical issues that, particularly in the context of climate policy, are most relevant for the choice of intertemporal discounting. The main purpose of this paper therefore is, to examine the ethical content of the existing justifications for unequal treatment of generations distinguishing between ethically less and more convincing reasons for intergenerational discounting. We use a simple axiomatic framework to derive our conclusions.

From our perspective, less convincing reasons for discounting are the description of actual behavior, the inclusion of a positive discount rate in order to prevent over-saving and some axiomatic justification based on Pareto-based arguments and completeness of an ordering requirements. More convincing arguments for discounting are the possible extinction of human mankind and the two axiomatic justifications based on egalitarian equivalence and the protection of the present.

This "justification" for intergenerational discounting essentially is as follows: Equal treatment of infinitely many generations in social evaluation is not possible if one wants to have egalitarian-equivalent consumption levels and/or protection of the present. These two normative postulates both are equity oriented. The conflict is between different equity norms. 


\section{DAS Wichtigste IN KÜRZE}

Die Bewertung von ökonomischen Projekten mit langem Zeithorizont ist ein ebenso lang wie heftig diskutiertes Thema in den Wirtschaftswissenschaften. Pionier bei der Untersuchung der Profitabilität von öffentlichen Projekten war der im 19. Jahrhundert lebende französische Ingenieur Jules Dupuit. Dupuits Konzept der Kosten-NutzenAnalyse wurde auch zur Abschätzung der langfristigen Effekte des Klimawandels angewendet. Aus der Tatsache heraus, dass Kosten von Vermeidungsmaßnahmen heute anfallen, der Nutzen jedoch erst in ferner Zukunft, spielt die Wahl des intertemporalen Wohlfahrtskriteriums eine entscheidende Rolle. Die Publikation des „Stern Reports“ 2006 hat die ethische Dimension des Problems betont und eine hitzige Debatte entfacht. Es scheint allerdings, dass einige Beiträge zu dieser Debatte, wie auch der „Stern Report“ selbst, normative und positive Argumente vermischen, um die eigene Position zu stärken.

In zwei kürzlich in der Fachzeitschrift „Environmental and Resource Economics“ veröffentlichten Beiträgen stritten Partha Dasgupta und John Roemer über die korrekte Interpretation der intertemporalen Wohlfahrtsökonomik. Unser Ziel ist es zu dieser Debatte beizutragen. Dabei wollen wir ökonomische und philosophische Argumente im Kontext der intertemporalen Evaluation des Klimawandels zusammenführen. Das wesentliche Anliegen dieser Arbeit ist, die ethische Stichhaltigkeit der vorgetragenen Argumente für oder gegen eine Ungleichbehandlung der Generationen zu überprüfen. Dabei verwenden wir einen einfachen axiomatischen Ansatz, um unsere Schlussfolgerungen zu ziehen.

Aus unserer Sicht sind die Beschreibung des von Individuen beobachteten Verhaltens, die Verwendung einer positiven Diskontrate zur Vermeidung exzessiv hoher Sparquoten und einige axiomatische Ansätze zur Begründung einer Ungleichbehandlung unterschiedlicher Generationen nicht hinreichend überzeugend. Die Möglichkeit des Aussterbens der menschlichen Spezies und die zwei Axiome der egalitären Äquivalenz und des Schutzes der heutigen Generation sind hingegen stichhaltiger. Eine Gleichbehandlung unendlich vieler Generationen ist nicht möglich, falls egalitär-äquivalente Konsumpfade angestrebt werden oder die gegenwärtige Generation beschützt werden soll. Beide normativen Postulate basieren auf Fairness-Überlegungen. 


\title{
HOW CAN PURE SOCIAL DISCOUNTING BE ETHICALLY JUSTIFIED?
}

\author{
WOLFGANG BUCHHOLZ* \& MICHAEL SCHYMURA ${ }^{\dagger}$
}

February 1, 2013

\begin{abstract}
The evaluation of long-term effects of climate change in cost-benefit analysis has a long tradition in environmental economics. Since the publication of the Stern Review in 2006 the debate about the "appropriate" discounting of future welfare and utility levels was revived and the most renowned scholars of the profession participated in this debate. In two recent contributions in Environmental and Resource Economics, there was dispute about intertemporal welfare economics between Partha Dasgupta and John Roemer about the correct interpretation of the topic. The aim of this work is to bring together economic and philosophical reasoning about justice and intergenerational equity in the context of climate change. So we adopt the normative view in order to present the most important ethical issues that, particularly in the context of climate policy, are most relevant for the choice of intertemporal discounting. Subsequently we explore whether ethical considerations may also be helpful to justify pure social discounting per se.
\end{abstract}

Keywords: Intertemporal ethics, Distribution, Discounting, Climate Change JEL-Classification: Q53

*University of Regensburg, Universitätsstraße 31, 93053 Regensburg, Germany; Email: wolfgang.buchholz@wiwi.uni-regensburg.de

${ }^{\dagger}$ Centre for European Economic Research (ZEW), L7,1, D-68161 Mannheim, Germany; Email: schymura@zew.de. Furthermore we thank the Wissenschaftsgemeinschaft Gottfried Wilhelm Leibniz (WGL) for funding. 


\section{INTRODUCTION}

VAluATION ACROSS TIME is a recurrent and highly contentious topic in economics. E The analysis of the profitability of public projects was introduced by Jules Dupuit, a french engineer (Sandmo, 2011). ${ }^{1}$ Dupuit's concept of cost-benefit analysis has also been used to evaluate the long-term effects of climate change. Due to the fact of today incurring costs and long-term benefits occurring in the future, the results from such longterm evaluations depend crucially from the chosen intertemporal welfare criterion. The publication of the Stern Review in 2006 has brought the ethical dimension of this issue to the fore and provoked a heated dispute. But it seems that some contributions dealing with the Stern Review, and the Review itself, mixed up normative and positive issues to defend the own position.

The debate about an "appropriate" discounting rate can characterized as a sharp dichotomy: On the one hand there are economists (e.g. William Nordhaus), who refuse ethical principles in determining the discount rate and who rely on the "invisible hand" of the market which determines the interest rate (the descriptive, positive approach). ${ }^{2}$ On the other hand no less renowned economists like (e.g. Nicholas Stern), who refuse a prohibition of mixing up economics with philosophy (the prescriptive, normative approach) (Buchholz and Schumacher, 2010). While the descriptive approach to discounting favors observable market rates, the prescriptive approach argues "that market rates cannot be used when looking across cohorts" (Aldy et al., 2010, p. 912). The participants in this debate have variously accused each other of ignorance of basic scientific knowledge (see Stern (2008)), "subconsciously" undertaking analysis to confirm the policy position of the UK Government (see Weitzman (2007)), or even trying to rekindle the British Empire (see Nordhaus (2007)). Independently, more recent contributions have shown that the discounting debate was not the only problem that needs to be reconciled. The main driver of dissonance in this strand of literature was the different interpretation of welfare economics. A prominent example is the reply by Partha Dasgupta on a suggestion in Roemer (2011) to use "sustainability" as a social welfare functional in order to avoid the weak ethical foundations of discounted utilitarianism. Dasgupta states, that Roemer is seriously affected by moral fundamentalism and that "he appears not to be able to read other. He [Roemer (2011)] seems to think that intergenerational welfare economics can be conducted satisfactorily only if it is confined to those theories that invoke his Ethical

\footnotetext{
${ }^{1}$ Dupuit analyzed 1844 how an estimate for the social profitability of a public project (e.g. a bridge) could be obtained. He mentioned, that costs are monetary but benefits are not and suggested the calculation by relying on utility (and therefore willingness to pay). His evaluation of a bridge as a public good "is the first example in the literature of an [...] cost-benefit analysis of a public project that is based on a rigorous theoretical foundation" (Sandmo, 2011, p. 156).

${ }^{2}$ The argumentation is based on the work of Eugen von Böhm-Bawerk and his "three reasons". The first reason is that people in average expect that more resources will be available for consumption in the future. The second reason is the shortsightedness of people underestimating future needs and the third reason is the "roundabout production", i.e. the idee that "trees produce more timber when one lets them grow longer, so other methods of production will be more productive when extend in time" (Sandmo, 2011, p. 185).
} 
Observer" (Dasgupta, 2011, p. 491). This writing is partly even more loaded than the debate about the discount rate.

In this paper, we adopt the normative view in order to present the most important ethical issues that, particularly in the context of climate policy, are most relevant for the choice of the appropriate method of intertemporal evaluation (see also Roemer (2011)), for an excellent defense of the ethical position). Both controversies around ethical questions that we have outlined above have been discussed for almost as long as cost-benefit analysis exist. The main topic of this discussion between economists (e.g. Pigou (1912); Ramsey (1928)) and philosophers (e.g. Sidgwick (1874) and Broome (1992, 1994)) is, whether it could be ethically justified to give later generations a lower weight than earlier ones or, to put it otherwise, whether intergenerational discounting is ethically defensible at all.

From the viewpoint of many philosophers, intergenerational discounting is "a device for unjustly promoting our own interests at the expense of our descendants" (Broome, 1994, p. 128). Basic fairness norms, i.e. impartiality, non-discrimination and equal treatment rule out the discounting practice. This means, that future levels of well-being ought not to be discounted just for the reason that they are on a different location on the time axis, everything else equal. Opposition against discounting can also be found among economists. Arthur Pigou held the viewpoint that "there is wide agreement that the State should protect the interests of the future in some degree against the effects of our irrational discounting and of our preference for ourselves over our descendants" (Pigou, 1932, pp. 29-30), a sentence similar to Ramsey's famous "lack of imagination". Robert Solows argumentation against intergenerational discounting of utility is in line with Pigou and Ramsey, stating that "[I]n social decision making, however, there is no excuse for treating generations unequally, and the time-horizon is, or should be, very long" (Solow, 1974a, p. 9). The supporters of intergenerational discounting often argue with the "fact", that future generations will be richer than our and hence it is legitimate to discount their well-being (Dasgupta, 2011), an argument that "puts the cart before the horse. We do not know that future societies will be "richer" than we are: whether or not that occurs will be an outcome of the policies we decide to implement - it cannot be taken as a premise" (Roemer, 2011, p. 374). However, the true ethical meaning of the argumentation has not been made explicit and sometimes it has even called into question (e.g Roemer, 2011), provoking harsh reactions from the opposite side.

The main purpose of this paper therefore is, to examine the ethical content of the existing justifications for unequal treatment of generations distinguishing between ethically less and more convincing reasons for intergenerational discounting. After this introduction we present the framework in section II. Then we will compare less and more convincing reasons for intergenerational discounting in the sections III and IV. Finally, we draw some tentative conclusions in section $\mathrm{V}$. 


\section{THE FRAMEWORK}

As common in the literature we assume that $c_{t}$ denotes well-being in each period $t=$ $1,2, \ldots$ This means that the vector of various determinants of well-being, i.e. material consumption, leisure, environmental quality etc, is mapped into the real-valued indicator $c_{t}$. The severe problems of measurement and aggregation of $c_{t}$ are not treated in this chapter. ${ }^{3}$ It is only for terminological convenience, that in the following the variable $c_{t}$ will be identified with consumption in period $t$. Time is discrete, with each period of time $t=1,2, \ldots$ representing just the lifespan of one single generation. So generations do not overlap, and for the sake of simplification, we suppose that population is constant over time thus neglecting the ethical aspects of population change. ${ }^{4}$ If some technology and some initial resource endowment are given there is a class $\Gamma$ of bounded paths $C=\left(c_{1}, c_{2}, \ldots\right)$ of well-being (i.e. "consumption") of an infinite number of non-overlapping generations and for all $t$. In our framework $R$ denotes a reflexive and transitive binary Social Welfare Relation (SWR) (quasi-order) on $\Gamma$ with $\sim$ as its symmetric and $P$ as its asymmetric part. If $R$ is also complete it is called a Social Welfare Order (SWO) (order). $R$ is represented by an intertemporal Social Welfare Function (SWF) $W($.$) defined on \Gamma$ if $W\left(C^{(2)}\right) \geq W\left(C^{(1)} \Leftrightarrow C^{(2)} R C^{(1)}\right.$ for all $C^{(1)}, C^{(2)} \in \Gamma$.

Roemer (1996) shows that if $W($.$) respects cardinal-unit-comparable information, it$ can be represented as a utilitarian social welfare function. Most frequently intertemporal evaluation is performed using discounted utilitarian social welfare functional, which gives utility of future generations less weight than utility of earlier ones. This type of social welfare functions is defined by

$$
W\left(c_{1}, c_{2}, \ldots\right)=\sum_{t=1}^{\infty} \delta_{t} u\left(c_{t}\right)
$$

In (1) the function $u\left(c_{t}\right)$ again represents utility of consumption and $\left(\delta_{t}\right)_{t=1,2, \ldots}$ is a nonincreasing sequence of utility discount factors with $\sum_{t=1}^{\infty} \delta_{t}<\infty$. These utility discount factors indicate how much utility in period $t$ counts in terms of period 1 . Therefore, $\delta_{1}=1$ and, if $\delta_{t}=1$ for all $t=1,2, \ldots$, undiscounted utilitarianism is obtained as a special case of (1). Traditionally, $\left(\delta_{t}\right)_{t=1,2, \ldots}$ is assumed to fall geometrically, i.e. $\delta_{t}=\delta^{t-1}$ where $\delta=\frac{1}{1-\rho}$ and $\rho \geq 0$ is the constant discount or time preference rate. ${ }^{5}$

\footnotetext{
${ }^{3} \mathrm{~d}$ 'Aspremont and Gevers (1977) offer a very comprehensive axiomatic approach towards different social welfare functionals. Roemer (1996) summarizes the extensive literature and contributions that deal with the measurability of well-being and its relevance for social welfare functional in a very elegant manner.

${ }^{4}$ We refer the reader who is interested in situations with a changing population to Blackorby et al. (1995).

${ }^{5}$ We emphasize this point, because there is seemingly a remaining confusion of what is being discounted with the discount rate or the discount factor.
} 
In applied economic research, an isoelastic von-Neumann-Morgenstern utility function with constant relative risk aversion (CRRA), is assumed. This was the case in e.g. Nordhaus and Boyer (2000); Nordhaus (2008); Dasgupta (2008) or Stern (2006):

$$
u\left(c_{t}\right)=\frac{c_{t}^{1-\eta}}{1-\eta}
$$

This utility function is not defined for $\eta=1$, such that the following restriction is necessary:

$$
u\left(c_{t}\right):= \begin{cases}\frac{c_{t}^{1-\eta}}{1-\eta} & \text { if } \eta \geq 0 \text { and } \eta \neq 1 \\ \ln \left(c_{t}\right) & \text { if } \eta=1\end{cases}
$$

To discuss the properties of discounted utilitarianism, we consider a very simple linear growth model with $\alpha>1$ as the time-invariant productivity parameter and with $k_{t}$ as the (physical) capital stock in period $t$. If $k_{t}$ is the capital stock available to generation $t$, it hands over the capital stock $k_{t+1}=\alpha\left(k_{t}-c_{t}\right)$ to the subsequent generation $t+1$.

\section{Less Convincing Reasons for Discounting}

\section{A Discounting as a Description of Actual Behavior}

The anti-ethicist position held by many economists rests upon the belief that economic valuation should be based on the (revealed) preferences and observable behavior of actual people who discount their own future utility and that of their descendants and that it should not be influenced by a purely abstract and eventually subjective ethical guidance like, for instance, intergenerational equity. The position can be summarized with the words of William Nordhaus: "I would interpret the baseline trajectory, form a conceptual point of view, as one that rpresents the outcome of market and policy factors as they currently exists. In other words, the DICE model is an attempt to project from a positive perspective [...] [and] this approach does not make a case for the social desirability of the distribution of incomes over space or time under existing conditions" (Nordhaus, 2008, p. 174).

The ethically oriented counter-position, also followed by many eminent economists, wants to keep ethical reflection within economics. Beside that one could note, that also the utilitarian social welfare functional is a normative concept per se, a fact that seems to be concealed by the positive economists, there are various arguments against the positive position. First, intergenerational evaluation refers to the treatment of unavoidably passive "third parties" and thus is not possible without ethics. Second, the picture of the selfish homo oeconomicus is antiquated as there are "other-regarding preferences" and their normative foundations are to be taken serious. And third, rational individuals want to make their ethically motivated choices in a coherent way The standard tools of economics are capable to deal with the properties (= foundations and implications) of different welfare criteria (in a dialectic process aiming at a "reflexive equilibrium" (Rawls (1971) 
and w.r.t. intertemporal evaluation especially Asheim (2010)). Therefore, economists should not prescribe specific normative judgments but they can help to make an ethical valuation more transparent and profound. As a consequence for the discounting debate, economists should also take into account the normative underpinnings of intergenerational discounting and not solely relying on observable behavior.

\section{B Discounting as Means to Prevent Over-Saving}

Applying a discounted utilitarian criterion is held to be an appropriate safeguard to avoid excessive savings of earlier generations. This widely held view dates back to Rawls (1971) who discussed (and refused) the applicability of his "difference principle" in the context of intergenerational equity. This is particularly clear if we start from a constant consumption path and any generation $t=2,3, \ldots$ has an equal increase in consumption $\epsilon$. Then given $\sum_{t=1}^{\infty} \delta_{t}<\infty$, the level of a welfare-improving investment in period 1 naturally is restricted by $\hat{s}=\left(\sum_{t=1}^{\infty} \delta_{t}\right) \epsilon$ which protects generation 1 . But, as explained above, along non-constant consumption paths the same effect may also be brought about with undiscounted social welfare functions. Moreover, if the utility function and the time discount factors are fixed, discounted utilitarianism mitigates but not necessarily avoids excessive savings of the first generation. We will show this using a linear growth model where the capital stock $k_{t+1}$ that generation $t$ hands over to generation $t+1$ is given by $k_{t+1}=\alpha\left(k_{t}-c_{t}\right)$. Here, $\alpha$ is a productivity parameter which is assumed to be constant over time and which indicates the marginal rate of transformation between consumption in period $t$ and period $t+1$. If $k_{t}$ is the initially given capital endowment of generation 1 then all consumption paths $\left(c_{1}, c_{2}, \ldots\right)$ are technically feasible for which

$$
\sum_{t=1}^{\infty} \frac{c_{t}}{\alpha_{t-1}} \leq k_{1}
$$

holds. Just as before we start from a constant consumption path $(\bar{c}, \bar{c}, \ldots)$ and assume that generation 1 makes an additional saving of $s$ units of consumption. Then it directly follows from (4) that this enables any subsequent generation to increase its consumption by $(\alpha-1) s$ units. If we now consider the special case of an isoelastic utility function with $\eta=1$, i.e. $\ln c$, the sum of discounted utilities flowing from some $s$ is

$$
\ln (\bar{c}-s)+\sum_{t=2}^{\infty} \delta^{t-1} \ln (\bar{c}+(\alpha-1) s)=\ln (\bar{c}-s)+\frac{\delta}{1-\delta} \ln (\bar{c}+(\alpha-1) s)
$$

By an easy calculation the level of savings which maximizes (5) is

$$
s^{*}=\frac{\delta \alpha-1}{\alpha-1} \bar{c}
$$

For even not quite eccentric values of $\delta$ and $\alpha$, as e.g. $\delta=0.9$ and $\alpha=1.25$, (6) implies that generation 1 would be forced to sacrifice $45 \%$ of its initial consumption to make 
future generations better off. If the productivity parameter $\alpha$ goes to infinity, the level of savings converges to $\delta \bar{c}$ which clearly shows that fixed social preferences will not prevent overburdening of generation 1 in any case, i.e. independent of the underlying technology. Concerning their ability to deal with the danger of excessive saving, the difference between undiscounted and discounted utilitarianism thus turns out to be less fundamental than might appear at first sight.

Stern (2006) rejects this ethical consideration for intergenerational discounting as not convincing and ad hoc. Discounting is not indispensable to avoid excessive saving. To demonstrate this property we rely on the linear growth model outlined above. The first order conditions along an optimal path in the linear growth model of the previous section are

$$
u^{\prime}\left(c_{t+1}\right)=\frac{1}{\delta \alpha} u^{\prime}\left(c_{t}\right)
$$

which for an isoelastic utility function means

$$
c_{t+1}=(\delta \alpha)^{\frac{1}{\eta}} c_{t}
$$

It follows from (8) that the same optimal path is obtained for different combinations of $\delta$ and $\eta$. In particular, the optimal solution, which results for some originally given parameter values $\delta$ and $\eta$, can also be implemented without any pure time discount, i.e. $\delta=1$, by-choosing a different inequality aversion parameter $\tilde{\eta}$ which is

$$
\tilde{\eta}=\frac{\eta \ln \alpha}{\ln \alpha+\ln \delta}
$$

This interchangeability of $\delta$ and $\alpha$ that, when choices among consumption paths are at stake, the gap between undiscounted and discounted utilitarianism is less deep than usually suspected.

In the analysis of (static) distributional problems inequality aversion of social preferences usually is measured through the elasticity of marginal utility $\eta$. Therefore one could raise the claim, that economists should not make things unnecessarily complicated in the intergenerational context by introducing a second instrument for the same purpose.

Stern (2006), in contrast to much previous work on climate change, explicitly addressed the ethical dimension of intergenerational evaluation which in particular meant that it in principle adopted the equal treatment postulate for generations deeply rooted in the prescriptive school. Therefore, in Stern's approach the elasticity of marginal utility $\eta$ automatically became the main tool for bringing about an ethically acceptable balance of interest between different generations. But, somewhat surprisingly, the highly crucial choice of $\eta$ was not discussed explicitly from the ethical viewpoint. In this context the reflections remained rather scanty, and no convincing normative justification for specifically choosing as inequality aversion index in the main part of the empirical study was given. At the central place of the Report (see (Stern, 2006, p. 184)) there is only a short remark that employing $\eta=1$ is "in line with recent empirical estimates". Reference, however, 
only is made to two empirical papers by Stern (1977) and Pearce and Ulph (1995), and it is not explained why such empirical estimates might at all be of much value for making ethical decisions. So coming to the choice of $\eta$, Stern (2006) does not contribute very much and, to some degree, even neglects his ethical intentions. The discussion after Stern (2006), however, has shown that ethically relevant arguments on the choice of $\eta$ can be found in three different ways.

Adopting an ethical perspective does not exclude that the ethical values of existing people become the standard of evaluation. Then the debate is not about what seems to be just in the eyes of an impartial and detached ethical observer but which altruistic attitudes are prevalent in a society. This approach, on which - without any further explanation and assessment - Stern (2006) draws on, combines prescriptive and descriptive elements but observed data do not come from the market-place but from political decisions where ethical motivations on distributional issues manifest. Although many political decisions (e.g. on pension reform and the size of the government deficit) clearly affect distribution between generations, it is very difficult, if not impossible to find out the level of underlying inequality aversion $\eta$. Therefore, results on individual preferences for redistribution that are obtained from empirical studies on the income tax system are transferred to the field of intergenerational distribution. The various studies on inequality aversion as expressed by income tax progressivity give quite different values for $\eta$ which in some studies lies in the interval between 1 and 2 (see Evans (2005)) but is lower in other studies (see Atkinson and Brandolini (2010)). These data certainly give some hint at existing normative beliefs on inequality. But the attitudes towards income distribution within a society are multi-dimensional and include aspects of effort and merit which are absent in the intergenerational context (where instead motivations as responsibility and stewardship play some role). So it may be doubted whether the estimates for $\eta$ that have been obtained from income tax studies can easily be applied to intergenerational evaluation and climate policy.

\section{Discounting as an Implication of Plausible Axioms on Intertemporal Wel- fare Criteria}

For consumption paths that are strictly bounded away from zero and bounded above social welfare according to (1) is a well-defined scalar such that a complete ordering is obtained. Since Koopmans (1960), discounting and thus unequal treatment has been derived from certain explicitly formulated postulates (or "axioms") which a plausible social welfare ordering should fulfill. ${ }^{6}$ The standard set of axioms for discounted utilitarianism consists of different versions of the Pareto principle, continuity conditions and completeness or cardinal representability postulates. In this section we will discuss the ethical content of those axioms.

${ }^{6}$ Note, however, that "Koopmans [...] did not did not argue that the DU [Discounted Utilitarianism] model was psychologically or normatively plausible; his goal was only to show that under some wellspecified (though arguably unrealistic) circumstances, individuals were logically compelled to possess positive time preference" (Frederick et al., 2002, p. 356). 
Pareto Principles

The most common version of the Pareto principle is the Strong Pareto (SP):

SP: Given two consumption streams $C^{(1)}=\left(c_{1}^{(1)}, c_{2}^{(1)}, \ldots\right)$ and $C^{(2)}=\left(c_{1}^{(2)}, c_{2}^{(2)}, \ldots\right)$ with $c_{t}^{(2)} \geq c_{t}^{(1)}$ for all $t=1,2, \ldots$ and $c_{t^{\prime}}^{(2)}>c_{t^{\prime}}^{(1)}$ for at least one $t^{\prime}$ then $C^{(2)} P C^{(1)}$.

A weaker version of SP is represented by Monotonicity (M) where only $C^{(2)} R C^{(1)}$ is implied by the same conditions. SP is completely uncontested in the case with a finite number of agents and there is no convincing argument why this should be different in the infinite case.

Continuity

For any topology $\tau$ on the set of consumption paths $\Gamma$ continuity $\mathbf{C O N}_{\tau}$ of an social welfare ordering is defined as follows:

$\mathbf{C O N}_{\tau}$ : Given two consumption paths $C^{(1)}$ and $C^{(2)}$ and some sequence $\left(\tilde{C}^{(n)}\right)_{n \in \mathbb{N}}$ the SWO $R$ is $\tau$-continuous if $\tilde{C}^{(n)} R C^{(1)}$ for all $n \in \mathbb{N}$ and $\lim _{n \rightarrow \infty} \tilde{C}^{(n)}=C^{(2)}$ imply $C^{(2)} R C^{(1)}$.

The choice of the underlying topology $\tau$ may exclude the possibility of equal treatment of all generations in a direct way.

Consider (generalized) Myopic Topologies $\tau_{m y o}$ (as in Brown and Lewis (1981)). These topologies are based on a distance function on $\Gamma \mathrm{x} \Gamma$ which is of the following type:

$$
d_{m y o}\left(C^{(1)}, C^{(2)}\right)=\sup _{t \in \mathbb{N}} \lambda_{t}\left|c_{t}^{(1)}-c_{t}^{(2)}\right|
$$

if $\left(\lambda_{t}\right)_{t \in \mathbb{R}}$ is a sequence of strictly positive real numbers with $\lim _{n \rightarrow \infty} \lambda_{t}=0$.

The equal treatment condition is captured by Finite Anonymity (FA).

FA: Let $\pi$ be a finite permutation of $\mathbb{N}$. For any $C=\left(c_{1}, c_{2}, \ldots\right) \in \Gamma$ then $\left(c_{\pi(1)}, c_{\pi(2)}, \ldots\right) \tilde{C}$.

The basic (and almost trivial) incompatibility result then is as follows.

S1: If a SWO $R$ is $\tau_{m y o}$-continuous and satisfies SP then it cannot fulfill FA.

Proof. Let $C^{(1)}=(c, 0,0, \ldots)$ for some $c>0, C^{(2)}=(0,0, \ldots)$ and $\tilde{C}^{(n)}=\left({\tilde{c_{1}}}^{(n)},{\tilde{c_{2}}}^{(n)}, \ldots\right)$ with $\tilde{c}_{t}^{(n)}=c$ if $t \neq n$ for all $n \in \mathbb{R}$. Assuming FA gives $\tilde{C}^{(n)} \tilde{C}^{(1)}$ and thus $\tilde{C}^{(n)} R C^{(1)}$ for all $n \in \mathbb{N}$. Since $d_{\text {myo }}\left(C(2), \tilde{C}^{(n)}=\lambda_{n} c\right.$ for all $n \in \mathbb{N}$ we get $\lim _{n \rightarrow \infty}^{\left(\tau_{\text {myo }}\right)} \tilde{C}^{(n)}=C^{(2)}$. $\mathbf{C O N}_{\tau_{\text {myo }}}$ then implies $C^{(2)} R C^{(1)}$. As $C^{(1)} P C(2)$ from $\mathbf{S P}$ this is a contradiction.

Given $\tau_{m y o}$-continuity results in shifting fixed consumption levels further and further into the future and is hence tantamount to a negligence in social evaluation. In other words, discrimination against future generations is already included in this specific type 
of topology. Furthermore, combining FA with SP implies a Dictatorship of the Future (DF) in the sense of Chichilnisky (1996). Many important topologies, as e.g. the strict myopic topology in Brown and Lewis (1981) and the product topology have the $\mathbf{C O N}_{\tau_{m y o^{-}}}$ property, except the Sup-Norm Topology $\tau_{\text {sup }}$ which is defined by the distance function $d\left(C^{(1)}, C^{(2)}\right)=\sup _{t \in \mathbb{N}}\left|c_{t}^{(1)}-c_{t}^{(2)}\right|$. The Sup-Norm Topology is, unlike the product topology, "neutral across generations when it comes to measuring the distance between any pair of elements" (Dasgupta, 2011, p. 481). An equal treatment of all generations in the underlying topology is only a minimum requirement for the choice of the topology. It does, however, not provide an ethically meaningful justification for using continuity conditions as basic axioms of intertemporal evaluation at all and to interpret it as truly moral axioms. A somewhat more profound reasoning is needed to reconcile continuity conditions with ethics. Rare attempts in the literature can be found in Banerjee and Mitra (2008) and Dasgupta (2011). In evaluating the necessity of continuity assumptions, Banerjee and Mitra write, that "[C]ontinuity has the important normative implication that rankings of streams are robust to any mis-specification of the streams" (Banerjee and Mitra, 2008, p. 2). However, this argument implicitly refers to decisions under risk and it thus departs from the theoretical framework in which a justification for discounted utilitarianism is usually looked for. Discussing the axiomatic justifications for maximin (by Hammond) and utilitarianism (by Maskin), Dasgupta write that "for example, pluralists are drawn to the requirement that $W$ be continuous because it accommodates trade-offs among people's felicities, something maximin prohibits" (Dasgupta, 2011, p. 485). But this argument refers to continuity on finite spaces. In the infinite setting continuity is much more difficult to grasp by intuition and Roemer asks: "Do our intuitions really grasp the import of requiring this condition on a social preference order?" (Roemer, 2011, p. 370$)$.

\section{Completeness}

In standard microeconomic theory completeness is a feature of the preferences attributed to the rational homo oeconomicus. A person should, for example, know whether she prefers a consumption bundle $A$ which consists of two apples and four oranges over a bundle $B$ which consists of four apples and two oranges. Furthermore, completeness does not require a cut back on other plausible properties of preferences. Completeness is an attractive feature if one shares the view that a rational ethical observer should always be able to decide whether one of two arbitrarily given consumption paths is better than the other (or whether they are equivalent). But it may be questioned how important completeness really is, i.e. whether "incompleteness (is) such a defect of an ethical theory" (Roemer, 2011, p. 370). So if the task is to choose a best element out of a class of technically feasible consumption paths one may be content with finding paths that dominate all other paths for a solely partial ordering, as e.g. the overtaking criterion as conceived by von Weizsäcker (1965) as a specific version of undiscounted utilitarianism. To some limited extent choices among consumption paths are well possible without having 
completeness. For instance, it is possible to exclude non-sustainable paths in productive technologies through application of the Suppes-Sen SWR (see Asheim et al. (2001)). From this perspective, dropping the equal treatment of generations as a basic equity norm may seem to be a too high price for getting completeness.

Reducing demands and becoming more modest in this way also reflects the view that it normally is quite unlikely that a single criterion integrates all properties that are normatively desirable. This problem is especially important when there are infinitely many agents/generations such that - since Diamond (1965) - impossibility results abound in the literature on intertemporal evaluation. In particular, it has been shown that a social ordering which fulfils the equal treatment postulate and the strong Pareto principle is not representable by a cardinal social welfare function when there is an infinite number of generations (see Basu and Mitra (2003)). Nevertheless, having a numerical welfare measurement makes the determination of optimal consumption paths simpler and more transparent, which - from a purely technical viewpoint - is a non-negligible advantage of discounted utilitarianism. But properly understood this argument cannot claim much ethical significance and therefore axiomatic approaches are no an ethically substantial justification of discounting.

\section{Convincing Reasons for Unequal Treatment of Generations}

\section{A Risk of Extinction of Human Mankind}

Since Sidgwick (1874) a major normative justification for intergenerational discounting refers to the exogenous risk that future generations might not exist (due to an asteroid or an unavoidable pandemic disease) ${ }^{7}$

Assume that the ethical observer is behind a veil of uncertainty and then applies expected utility theory. If the different states of the world will not occur with the same probability she will take these differences into account when she makes her assessment even if, in principle, she is impartial and does not favor any position. In the intergenerational context this argument implies that it is ethically well acceptable to give later generations some lower weight in social evaluation since there is some risk that mankind may be extinct and thus later generations that can enjoy the fruits of savings today do not exist. If this risk of extinction from one period to the next is assumed to be constant over time and equal to $\pi$ the discount factor in period $t$ is equal to the probability of survival $\delta_{t}=(1-\pi)^{t-1}$. Estimation of clearly is very speculative and a matter of subjective belief. In particular, Stern (2006) has assumed a probability of $10 \%$ that civilization may be extinct within one century which implies an annual utility discount rate $\rho=0.1 \%$ p.a. . From the ethical standpoint it may also seem questionable to make such a bet on the existence of future generations. "Gambling" on the existence of future generations may seem morally questionable: Is it ethically legitimate to give utility of other people lower weight because they may die before they get benefit of? Also other risks, related

${ }^{7}$ See also Dasgupta and Heal (1979) for an extensive discussion on this. 
to changes of technology or preferences, deserve attention too which might take away any selectivity from this approach.

In the following another route is taken. The idea is to substitute some of the standard axioms by simple new ones which have a more straightforward ethical appeal. (To keep things simple minimization of assumptions is not aimed at.)

\section{B Egalitarian Equivalence}

The existence of egalitarian-equivalent consumption streams appears in most of the standard axiomatic approaches (from Koopmans (1960) and Diamond (1965) to Asheim, Mitra and Tungodden, 2012, and Mitra and Ozbek, 2012) as an implication of other assumptions. Egalitarian Equivalence (EE) appears only in some contributions (e.g. Bleichrodt, Rohde and Wakker, 2008) as an explicit axiom.

EE: Given an SWO $R$ for any consumption path $C \in \Gamma$ there is a unique consumption level $\hat{c}(C)$ so that $(\hat{c}(C), \hat{c}(C), \ldots) \tilde{C}$.

Why is EE an important property of social preferences which deserves it to be considered as an independent axiom? Since Atkinson (1970) egalitarian-equivalent consumption profiles are a standard tool in the analysis of distributional problems. EE allows it to compare the degree of inequality aversion of different social preferences: A smaller $\hat{c}(C)$ for given $C$ indicates a higher inequality aversion of the underlying SWO. Based on this it is possible in the standard way to assess the "price" of attaining an equal distribution of consumption across generations, as usual in Atkinson's approach. Assume that given a specific technology and some initial endowment there exists a maximum sustainable consumption level $\bar{c}$ as well as a unique consumption stream $C^{*}$ which is optimal w.r.t. the given social preferences. Then $\hat{c}\left(C^{*}\right)-\bar{c}$ is an indicator of the loss which has to be accepted in order to achieve constant consumption over time. A weak continuity assumption which combined with SP gives EE is Scalar Continuity $\mathbf{C O N}_{s c a}$ (Mitra and Ozbek, 2012).

$\mathbf{C O N}_{s c a}$ : A SWO $R$ is scalar continuous if for any consumption path $C \in \Gamma$ the sets $c \geq 0:(c, c, \ldots) R C$ and $c \geq: C R(c, c, \ldots)$ are closed subsets of $\mathbb{R}$.

$\mathbf{C O N}_{s c a}$ furthermore is implied by other types of continuity as Restricted Continuity $\mathbf{C O N}_{r e s}$ (Asheim, Mitra and Tungodden, 2012) or Sup-Norm Continuity $\mathbf{C O N}_{\text {sup }}$.

The impossibility result which shows the incompatibility between treating generations equally and having egalitarian-equivalent paths is as follows:

S2: If a SWO $R$ satisfies SP and EE it cannot have FA.

Proof. The assertion directly follows from Basu and Mitra (2003) since $\hat{c}(C)$ is a cardinal representation of the underlying SWO. 
Introducing an additional axiom (Constancy of Egalitarian-Equivalent Consumption Over Time (CE) gives a somewhat weaker, but more intuitive version of S2.

CE: For any path $C=\left(c_{1}, c_{2}, \ldots\right) \in \Gamma$ for which an egalitarian-equivalent consumption level $\hat{c}(C)$ exists $\hat{c}\left(\hat{c}(C), c_{1}, c_{2}, \ldots\right)=\hat{c}(C)$ holds.

CE is ensured by well-known assumptions as Independent Future (IF) or Stationarity (ST).

S3: If a SWO $R$ satisfies $\mathbf{S P}, \mathbf{E E}$ and $\mathbf{C E}$ it cannot have FA.

Proof. Let $C^{(1)}=\left(c_{a}, c_{b}, c_{b}, \ldots\right)$ for some arbitrarily chosen $c_{a}$ and $c_{b}$ with $c_{a}<c_{b}$ be given. $\mathbf{C E}$ gives $C^{(2)}=\left(\hat{c}\left(C^{(1)}\right), c_{a}, c_{b}, c_{b}, \ldots\right) \tilde{C}^{(1)}$ where existence of a unique $\hat{c}\left(C^{(1)}\right.$ follows from EE. SP implies $\hat{c}\left(C^{(1)}<c_{b}\right.$ and then $C^{(3)}=\left(c_{b}, c_{a}, c_{b}, c_{b}, \ldots\right) P C^{(2)}$. Hence, from transitivity $C^{(3)} P C^{(1)}$. But $C^{(3)}$ is obtained from $C^{(1)}$ by permuting consumption of generations 1 and 2 so that with FA we would have $C^{(3)} \tilde{C}^{(1)}$ which is a contradiction.

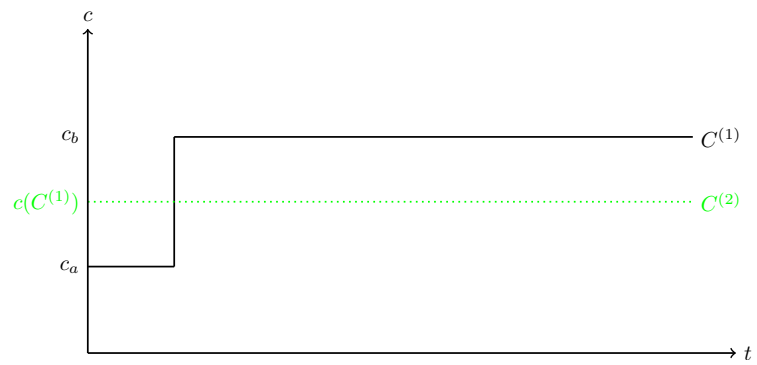

(a)

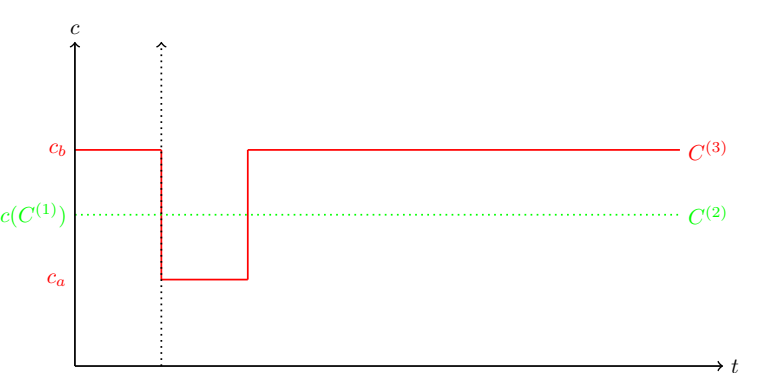

(b)

In the context of EE there is another impossibility result which is related to another type of equity norms reflected e.g. by the Pigou-Dalton Transfer Principle PDT (e.g. Fleurbaey and Michel, 2001, Bossert, Sprumont and Suzumura, 2007, and Hara et al., 2008).

PDT: For any $\left.C^{(1)}=\left(c_{1}^{(} 1\right), c_{2}^{(1)}, \ldots\right)$ and $C^{(2)}=\left(c_{1}^{(2)}, c_{2}^{(2)}, \ldots\right)$ with $c_{t_{1}}^{(2)}=c_{t_{1}}^{(1)}+\Delta \leq$ $c_{t_{2}}^{(1)}-\Delta=c_{t_{2}}^{(2)}$ some $\Delta>0$ and two periods $t_{1}$ and $t_{2}$ and $c_{t}^{(2)}=c_{t}^{(1)}$ for all periods $t \neq t_{1}, t_{2}$ it holds that $C^{(2)} P C^{(1)}$.

S4 If a SWO $R$ satisfies SP and EE it cannot have PDT.

Proof. Let again $C^{(1)}=\left(c_{a}, c_{b}, c_{b}, \ldots\right)$ for some arbitrarily chosen $c_{a}$ and $c_{b}$ with $c_{a}$ $<c_{b}$ be given. Then consider the consumption path $C^{(2)}=\left(c_{1}^{(2)}, c_{2}^{(2)}\right.$ which is defined by $c_{t}^{(t)}=\hat{c}\left(C^{(1)}\right.$ for all $t=1, \ldots, s-1, c_{s}^{(2)}=c_{b}-\epsilon$ and $c_{t}^{(2)}=c_{b}$ for all $t=s+1, s+2, \ldots$ where $s \geq 2$ and $\epsilon>0$ are chosen so that $\hat{c}\left(C^{(1)}\right)-c_{a}=(s-2)\left(c_{b}-\hat{c}\left(C^{(1)}\right)+\epsilon\right.$. This construction can be made since $\mathbf{S P}$ implies $c_{a}<\hat{c}\left(C^{(1)}\right)<c_{b}$. The path $C^{(2)}$ can be 
obtained from $C^{(1)}$ through a finite sequence of Pigou-Dalton transfers so that $C^{(2)} P C^{(1)}$ from PDT. But SP and EE give that $C^{(2)} P C^{(1)}$ since $C^{(2)} P\left(\hat{c}\left(C^{(1)}\right), \hat{c}\left(C^{(1)}\right), \ldots\right)$ and $\left(\hat{c}\left(C^{(1)}, \hat{c} C^{(1)}, \ldots\right) \tilde{C}^{(1)}\right.$ which is a contradiction.

S4 also holds for Altruistic Equity (AE) (see Hara et al. 2008) instead of PDT (see Alcantud, 2011).

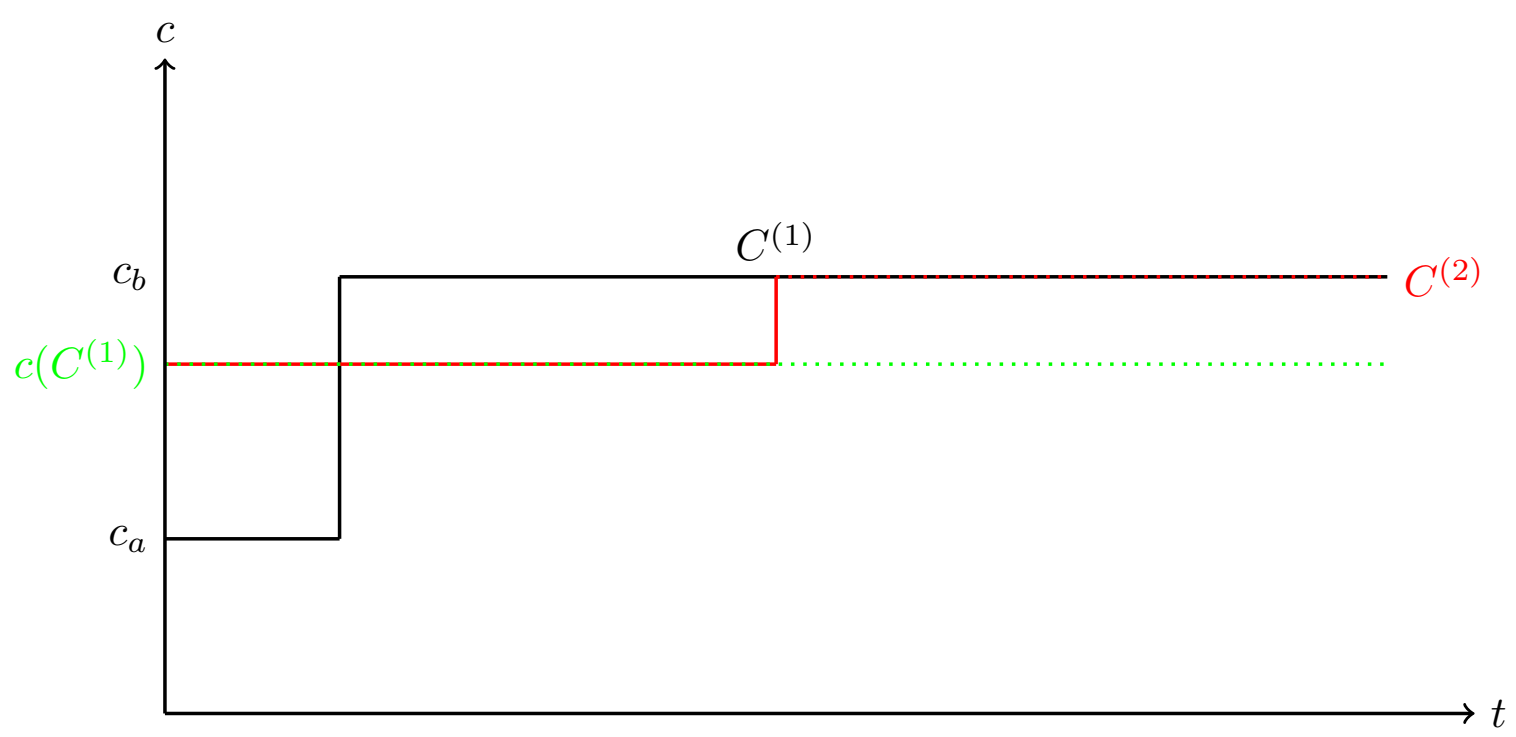

Note that EE and PDT refer to the same type of equity norms, i.e. equality of distribution.

\section{Protection of the Present}

The idea that oversaving by the present generation should be avoided in any case (see Asheim (2010)) can be avoided directly by imposing a Protection of the Present (POP) axiom.

POP: Let any non-decreasing consumption path $C^{(1)}=\left(c_{1}^{(1)}, c_{2}^{(2)}, \ldots\right)$ be given. Then for any tail ${ }_{2} C^{(2)}=\left(c_{2}^{(2)}, c_{3}^{(2)}, \ldots\right)$ with $c_{t}^{(2)} \geq c_{t}^{(1)}$ and $c_{t}^{(2)}-c_{t}^{(1)} \leq \epsilon$ for some $\epsilon>0$ and all $t=$ $2,3, \ldots$ there exists a consumption level $\left.\tilde{c}_{12} C^{(2)}\right)>0$ so that $\left(\tilde{c}_{1}\left({ }_{2} C^{(2)}, c_{2}^{(2)}, c_{3}^{(2)}, \ldots\right) \tilde{C}^{(1)}\right.$.

The ensuing impossibility result is closely related to that in $\mathbf{S 3}$.

S5 If a SWO $R$ satisfies SP, POP, CE it cannot have FA.

Proof. Take $C^{(1)}=(c, c, \ldots)$ and ${ }_{2} C^{(2)}=(c+\epsilon, c+\epsilon, \ldots)$ for some $\epsilon>0$. Then POP ensures that for $\left(\tilde{c}_{1}\left({ }_{2} C^{(2)}, c+\epsilon, c+\epsilon, \ldots\right)\right.$ an egalitarian-equivalent path exists which is equal to $C^{(1)}$. The further proof follows that of $\mathbf{S 3}$. 


\section{Conclusion}

The potential normative "justification" for intergenerational discounting which flows from the previous considerations essentially is as follows: Equal treatment of infinitely many generations FA in social evaluation is not possible if one wants to have egalitarianequivalent consumption levels EE and/or protection of the present POP (combined with Strong Pareto SP). Note that these two normative postulates both are equity oriented. The conflict is between different equity norms.

There are some reasons which mitigate this conflict just for practical applications but which may also cause new challenges.

(i) DU Light?

If one accepts (as in Stern (2006)) that the risk of extinction justifies an albeit very small pure discount rate the trade-offs between the standard axioms are no longer very important: In principle, the equal treatment norm is still endorsed while the fulfillment of the other ethical postulates does not depend on the level of the pure discount rate. But ethical reasoning then is shifted to the determination of specific parameters in the SWF, i.e. to choosing the levels of the discount rate and the elasticity of marginal utility. Conceptually, this seems to be a less fundamental matter than the "pure" discount rate debate. The dispute on the Stern Review however shows: There is room for much fierce controversy also here - and only few systematic ethical arguments are provided in this context. But see Dasgupta (2008) and Buchholz and Schumacher (2010).

(ii) Endogenous Social Preferences?

If pure intergenerational discounting is used to avoid oversaving discrimination against future generations in the social evaluation criterion does not manifest itself in discrimination w.r.t. consumption opportunities. The 'pure' discounting debate therefore in a certain sense becomes irrelevant. But the intergenerational distribution of consumption then will vary extremely with the underlying technology when the discount rate is fixed. E.g. in the linear growth model with an isoelastic utility function the growth rate of consumption is $g=(\alpha \delta)^{\frac{1}{\eta}}-1$. If notions of fair intergenerational distributions refer to the level of the growth rate $g$ (as in Llavador, Roemer and Silvestre, 2008) the discount factor $\delta$ has to depend on the productivity parameter $\alpha$. Constant consumption over time $g=0$ as the limiting case of growth is achieved by setting $\delta=\frac{1}{\alpha}$. Then from the beginning intergenerational discounting "has no intrinsic ethical appeal. It is introduced in a purely ad hoc way to moderate the consequences of the (undiscounted, W.B.) utility criterion" (Rawls, 1971, p. 298). At the same time the usual idea of fixed social preferences incorporating specific normative postulates has to be abandoned. 


\section{REFERENCES}

Aldy, J., Krupnick, A., Newell, R., Parry, I. and Pizer, W. (2010): Designing Climate Mitigation Policy, in: Journal of Economic Literature, Vol. 48, pp. 903-934.

Asheim, G.B., Buchholz, W. and Tungodden B. (2001): Justifying Sustainability, in: Journal of Environmental Economics and Management, Vol. 41, pp. 252-268.

Asheim, G.B. (2010): Intergenerational Equity, in: Annual Review of Economics, Vol. 2, pp. 197-222.

AtKinson, A. (1970): On the Measurement of Inequality, in: Journal of Economic Theory, Vol. 2, pp. 244-263.

Atkinson, A. and Brandolini, A. (2010): On Analyzing the World Distribution of Income, in: World Bank Economic Review, Vol. 24, pp. 1-37.

BANerJeE, K. and Mitra, T. (2008): On the continuity of ethical social welfare orders on infinite utility streams, in: Social Choice and Welfare, Vol. 30, pp. 1-12.

Basu, K. and MitrA, T. (2003): Aggregating Infinite Utility Streams with Intergenerational Equity: The Impossibility of Being Paretian, in: Econometrica, Vol. 71, pp. $1557-1563$.

Blackorby C., Bossert, W. and Donaldson, D. (1995): Intertemporal Population Ethics: Critical-Level Utilitarian Principles, in: Econometrica, Vol. 63, pp. 1303-1320.

Broome, J. (1992): Counting the cost of global warming, The White Horse Press, Cambridge, UK, 1992.

Broome, J. (1994): Discounting the future, in: Philosophy and Public Affairs, Vol. 23, pp. $128-156$.

Brown, D. and Lewis, L. (2003): Myopic Economic Agents, in: Econometrica, Vol. 49, pp. 359-368.

Buchholz, W., and Schumacher, J. (2010): Discounting and welfare analysis over time: Choosing the $\eta$, in: European Journal of Political Economy, Vol. 26, pp. 372-385.

Chichilnisky, G. (1996): An axiomatic approach to sustainability, in: Social Choice and Welfare, Vol. 13, pp. 231-257.

D‘Aspremont, C. and Gevers, L. (1977): Equity and the Informational Basis of Collective Choice, in: The Review of Economic Studies, Vol. 44, pp. 199-209.

Dasgupta, P. and Heal, G. (1979): Economic Theory and Exhaustible Resources, Cambridge University Press, Cambridge, UK. 
DASGUPTA, P. (2008): Discounting climate change, in: Journal of Risk and Uncertainty, Vol. 37, pp. 141-169.

DASGUPTA, P. (2011): The Ethics of Intergenerational Distribution: Reply and Response to John E. Roemer, in: Environmental and Resource Economics, Vol. 50, pp. 475-493.

Diamond, P. (1965): The Evaluation of Infinite Utility Streams, in: Econometrica, Vol. 33, pp. 170-177.

Evans, D. (2005): The Elasticity of Marginal Utility of Consumption: Estimates for 20 OECD Countries, in: Fiscal Studies, Vol. 26, pp. 197-224.

Frederick, S., Loewenstein, G. and O'Donoghue, T. (2002): Time Discounting and Time Preference: A Critical Review, in: Journal of Economic Literature, Vol. 40, pp. 351-401.

HaRsanYI, J.C. (1955): Cardinal Welfare, Individualistic Ethics, and Interpersonal Comparisons of Utility, in: Journal of Political Economy, Vol. 63, pp. 309-321.

Koopmans, T. (1960): Stationary Ordinal Utility and Impatience, in: Econometrica, Vol. 28, pp. 287-309.

Nordhaus, W., and Boyer, J. (2000): Warming the World - Economic Models of Global Warming, MIT Press Cambridge, MA, 1994.

Nordhaus, W. (2007): A review of the Stern Review on the economics of climate change, in: Journal of Economic Literature, Vol. 45, pp. 686-702.

Nordhaus, W. (2008): A Question of Balance, Yale Universtiy Press, New Haven, USA, 2008.

Pearce, D. and Ulph, D. (1995): A Social Discount Rate for the United Kingdom, in: Global Environmental Change Working Paper GEC-1995-01.

Pigou, A. (1912): Wealth and Welfare, MacMillan and Co., London, UK, 1912.

Pigou, A. (1932): Wealth and Welfare, MacMillan and Co., $4^{\text {th }}$ edition, London, UK, 1932.

RAMSEY, F. (1928): A mathematical theory of saving, in: The Economic Journal, Vol. 38, pp. 543-559.

RAwLs, J. (1971): A Theory of Justice, The Belknap Press of the Harvard University Press, Cambridge, MA, 1971.

Roemer, J. (1996): Theories of Distributive Justice, Harvard University Press, Cambridge, MA, USA, 1996. 
RoEmer, J. (2011): The Ethics of Intertemporal Distribution in a Warming Planet, in: Environmental and Resource Economics, Vol. 48, pp. 363-390.

SANDmo, A. (2011): Economics Evolving: A History of Economic Thought, Princeton University Press, Princeton, NJ, USA.

SIDGWICK, H. (1874): The Methods of Ethics, Oxford University Press, Oxford, UK.

Solow, R. (1974a): The Economics of Resources or the Resources of Economics, in: The American Economic Review: Papers \& Proceedings, Vol. 64, pp. 1-14.

Stern, N. (1977): The Marginal Valuation of Income, in: Studies in Modern Economic Analysis: The Proceedings of the Association of University Teachers of Economics, ed. M. J. Artis and A. R. Nobay, pp. 209-254, Basil Blackwell, Oxford, UK.

Stern, N. (2006): The Economics of Climate Change: The Stern Review, Cambridge University Press, 2006.

Stern, N. (2008): The Economics of Climate Change, in: The American Economic Review: Papers \& Proceedings, Vol. 98, pp. 1-37.

VON WeizsäCKer, C.C. (1965): Existence of Optimal Programs of Accumulation for an Infinite Time Horizon, in: Review of Economic Studies, Vol. 32, pp. 85-104.

Weitzman, M. (2007): A Review of The Stern Review on the Economics of Climate Change, in: Journal of Economic Literature, Vol. 45, pp. 703-724 